\title{
LOS DERECHOS DIGITALES EN EL ÁMBITO LABORAL: COMENTARIO DE URGENCIA A LA LEY ORGÁNICA 3/2018, DE 5 DE DICIEMBRE, DE PROTECCIÓN DE DATOS PERSONALES Y GARANTÍA DE LOS DERECHOS DIGITALES
}

\author{
Raquel Serrano Olivares \\ Profesora Titular de Derecho del Trabajo y la Seguridad Social \\ Universitat de Barcelona
}

\begin{abstract}
El objeto del presente articulo es analitzar la nueva Ley Orgánica 3/2018, de 5 de diciembre, de Protección de Datos Personales y Garantía de los Derechos Digitales, que regula específicamente el derecho a la protección de datos personales en el ámbito laboral e incorpora un nuevo derecho digital de contenido laboral como es el derecho a la desconexión.
\end{abstract}

The aim of this article is to analyze the new Organic Law 3/2018, of December 5, on the Protection of Personal Data and the Guarantee of Digital Rights, which specifically regulates the right to the protection of personal data in the workplace and incorporates a new digital right of labor content such as the right to disconnection.

Title: Digital rights in the workplace: urgent comment to Organic Law 3/2018, December 5, protection of personal data and guarantee of digital rights

Palabras clave: protección de datos personales, derechos digitales, intimidad, videovigilancia, geolocalización, desconexión digital.

Keywords: personal data protection, digital rights, privacy, video surveillance, geolocation, digital disconnection.

IUSLabor 3/2018, ISSN 1699-2938, pp 216-229

10.31009/IUSLabor.2018.i03.06

\section{Sumario}

1. Introducción

2. Uso de dispositivos digitales en el ámbito laboral

3. Uso de dispositivos de videovigilancia y de grabación de sonidos en el ámbito laboral

4. Uso de sistemas de geolocalización en el ámbito laboral 
5. Derecho a la desconexión digital en el ámbito laboral

6. Derechos digitales en la negociación colectiva

7. Tratamiento de datos personales en el marco de procesos de modificación estructural de sociedades o transmisión de negocio o rama de actividad empresarial 


\section{Introducción}

La nueva Ley Orgánica 3/2018, de 5 de diciembre, de Protección de Datos Personales y Garantía de los Derechos Digitales, que entró en vigor el 7 de diciembre, ha reemplazado a la Ley Orgánica 15/1999, de 13 de diciembre, de Protección de Datos Personales, a fin de complementar y adaptar nuestra normativa interna al Reglamento (UE) 2016/679 del Parlamento Europeo y del Consejo, de 27 de abril de 2016, relativo a la protección de las personas físicas en lo que respecta al tratamiento de datos personales y a la libre circulación de estos datos y por el que se deroga la Directiva 95/46/CE (Reglamento general de protección de datos), aplicable desde el 25 de mayo de 2018.

La nueva Ley Orgánica regula específicamente el derecho a la protección de datos personales en el ámbito laboral e incorpora un nuevo derecho digital de contenido laboral como es el derecho a la desconexión, siguiendo en este punto a otros ordenamientos jurídicos de nuestro entorno.

Hasta la fecha, la ausencia de una regulación específica del derecho a la protección de datos de carácter personal en el ámbito laboral había sido colmada mediante las doctrinas jurisprudenciales del Tribunal Constitucional y del Tribunal Supremo, que habían generado un cuerpo consolidado de criterios interpretativos y aplicativos en esta materia, no exento de fricciones con la doctrina emanada del Tribunal Europeo de Derechos Humanos. El nuevo marco legal contempla ahora reglas específicas en materia de uso de dispositivos digitales, videovigilancia, grabación de sonidos y geolocalización en el ámbito laboral.

Sin embargo, la nueva regulación aporta más sombras que luces al desarrollo de los derechos digitales en el ámbito laboral, en la medida en que genera importantes dudas interpretativas, que solo podrán resolverse a medio plazo merced a la tarea interpretativa/aplicativa de los órganos judiciales de lo social. Interesa, por tanto, analizar brevemente los principales elementos de cambio en cada una de las materias indicadas.

\section{Uso de dispositivos digitales en el ámbito laboral}

En primer lugar, el artículo 87 de la Ley Orgánica 3/2018 regula el "derecho a la intimidad y el uso de dispositivos digitales en el ámbito laboral", viniendo a establecer expresamente como límite al poder de control empresarial del uso de los dispositivos digitales el derecho a la intimidad de los trabajadores/as y empleados/as públicos. Dicho reconocimiento expreso ha supuesto la modificación del Estatuto de los Trabajadores y 
del Estatuto Básico del Empleado Público (Disposición final 13 ${ }^{\mathrm{a}}$ de la Ley Orgánica 3/2018), a fin de recoger los derechos de los trabajadores/as a la intimidad en el entorno digital y a la desconexión, resultando sorprendente, a nuestro juicio, que no se aluda al derecho a la protección de datos de carácter personal en cuanto derecho fundamental autónomo y diferenciado del derecho a la intimidad, así como al derecho al secreto de las comunicaciones.

Esta nueva previsión constituye una regulación relativamente novedosa, por cuanto que el Tribunal Constitucional, a través de una consolidada doctrina, ya había establecido desde antiguo que los derechos fundamentales -incluido el derecho a la intimidadactúan como límite a los poderes del empresario en el ámbito laboral.

Mayor relevancia reviste el expreso reconocimiento de dos concretos deberes empresariales en este ámbito. De un lado, el deber de elaborar una política de uso de los dispositivos digitales, y, de otro lado, el deber de informar a los trabajadores/as sobre tales criterios de uso.

La nueva regulación parte de posibilitar el acceso del empleador a los contenidos derivados del uso de medios digitales facilitados a los trabajadores/as, a efectos de controlar el cumplimiento de las obligaciones laborales o estatutarias y de garantizar la integridad de dichos dispositivos, sin necesidad de consentimiento por parte de aquéllos. Sin embargo, el acceso a los dispositivos digitales exige que el empleador establezca los criterios de utilización de los mismos e informe a los trabajadores/as sobre ellos; exigencia que se refuerza en los casos en que el empleador haya permitido usos privados, ya que en estos supuestos aquél deberá especificar de modo preciso los usos autorizados y establecer garantías para preservar la intimidad de los trabajadores, tales como, en su caso, la determinación de los períodos en que los dispositivos podrán utilizarse para fines privados.

No aparecen delimitados en la ley los efectos de un eventual incumplimiento del deber de información por parte de la empresa, planteándose la duda de si el legislador ha pretendido o no situar el deber/derecho de información dentro del contenido esencial de los derechos a la intimidad y a la protección de datos de carácter personal. En nuestra opinión, el derecho a la información se inserta en el contenido esencial de los derechos citados, de tal manera que el incumplimiento del deber de información conllevaría la vulneración de tales derechos.

Respecto a los criterios de utilización de los dispositivos digitales, interesa precisar que el legislador parece considerar legítima la decisión empresarial de prohibir totalmente el uso para fines personales de internet y de otros dispositivos digitales conexos de 
titularidad empresarial, sin atender a consideraciones relativas a la difícil delimitación entre vida profesional y vida privada y al uso social de las nuevas tecnologías de la comunicación.

Como novedad relevante en este ámbito, es preciso destacar que la ley exige expresamente, aunque sin mayores precisiones, la participación de la representación del personal en la elaboración de los criterios de uso de dispositivos digitales. No resulta evidente si esta nueva previsión supone el reconocimiento de un nuevo derecho en favor de la representación del personal, que se suma al ya previsto en el artículo 64.5 f) ET, o bien si se trata de una mera concreción de lo dispuesto en el citado artículo 64.5 f) ET en materia de control de los dispositivos digitales. Especialmente útil a efectos de clarificar esta cuestión hubiera resultado la reforma del actual artículo 64 ET, a fin de recoger expresamente esta previsión.

Resulta igualmente dudoso el alcance del deber/derecho de información. De entrada, parece que la mera prohibición -total o parcial- del uso personal de los dispositivos digitales habilita la vigilancia empresarial, sin que el empleador deba informar expresamente a los trabajadores/as de la finalidad, naturaleza y alcance del control, así como del grado de intrusión en su intimidad. Interpretada de este modo, la nueva regulación se alinearía perfectamente con la vigente doctrina del Tribunal Constitucional y del Tribunal Supremo.

Con todo, la conclusión alcanzada no parece del todo segura, habida cuenta que la nueva ley exige también que los empleadores, a la hora de fijar los criterios de utilización de los dispositivos digitales "respeten en todo caso los estándares mínimos de protección de la intimidad de acuerdo con los usos sociales y los derechos reconocidos constitucional y legalmente". En nuestra opinión, esta previsión debe interpretarse a la luz de la doctrina del Tribunal Europeo de Derechos Humanos en el asunto Barbulescu II (sentencia de 5 de septiembre de 2017), donde se razona que las instrucciones de un empresario en el sentido de prohibir el uso personal de los medios tecnológicos de la empresa no pueden reducir a la nada el ejercicio de la vida privada social en el lugar de trabajo, de modo que el respeto a la vida privada y a la confidencialidad de las comunicaciones continúa imponiéndose, aunque éstas puedan limitarse en la medida necesaria para satisfacer los intereses empresariales. Consiguientemente, los/as empleados/as tienen derecho a ser informados previamente por parte de su empresa de la finalidad, naturaleza y alcance del control, así como del grado de intrusión en su vida privada. De este modo, el Tribunal europeo sitúa el derecho de información previa dentro del contenido esencial del derecho al respeto de la vida privada y la correspondencia (art.8 CEDH). 
Dicho de otra manera: la expectativa de intimidad y secreto de las comunicaciones sigue vigente, aunque exista una prohibición empresarial expresa y absoluta del uso personal de los dispositivos digitales, salvo que el empleador informe con la debida antelación de la naturaleza, tipo y alcance del control, así como del grado de intrusión en la vida privada social (la que se desarrolla en el lugar de trabajo).

Sin embargo, es preciso subrayar que no basta con dar cumplimiento al derecho de información previa en el sentido amplio ya expuesto, sino que el control empresarial sobre los dispositivos digitales debe ajustarse, además, al principio de proporcionalidad, de tal manera que los tribunales deberán valorar, en primer lugar, las concretas razones que justifican la puesta en práctica de determinados medios de control especialmente intrusivos; en segundo lugar, la existencia o no de mecanismos de control menos invasivos de la intimidad y la correspondencia, y, en tercer lugar, y en base a las anteriores consideraciones, si resulta o no justificado o proporcionado acceder, en su caso, al contenido de las comunicaciones. En este sentido se expresa el Tribunal Europeo de Derechos Humanos en su sentencia Barbulescu II.

La nueva regulación no se refiere expresamente al debido respeto al principio de proporcionalidad, si bien la aplicación de dicho principio debe inferirse de la previsión legal relativa a que los criterios de utilización de los dispositivos digitales deben respetar "en todo caso los estándares mínimos de protección de la intimidad de acuerdo con los usos sociales y los derechos reconocidos constitucional y legalmente". Consiguientemente, el acceso del empleador a los contenidos derivados del uso de dispositivos digitales deberá regirse por el principio de proporcionalidad, sin que la mera información previa sobre los usos concretos pueda suponer un cheque en blanco al poder de control empresarial.

A propósito del principio de proporcionalidad, interesa destacar también que la ley posibilita el acceso a los "contenidos" derivados del uso de dispositivos digitales, generando la duda de si tal expresión se refiere o no al contenido de las comunicaciones, afectando, así, al derecho fundamental al secreto de las comunicaciones. Entendemos que la expresión empleada debe interpretarse restrictivamente, por cuanto que no siempre resultará proporcionado acceder al "contenido" de las comunicaciones a fin de comprobar el cumplimiento de las obligaciones laborales, bastando, a menudo, con un control del flujo de las comunicaciones u otros medios alternativos.

A la vista de lo expuesto, podemos concluir que el debate sobre los límites al control empresarial en el uso de los dispositivos digitales sigue abierto y que la nueva regulación no ha venido a zanjar definitivamente la cuestión. Con todo, parece que el nuevo marco normativo viene a refrendar la vigente doctrina del Tribunal 
Constitucional y del Tribunal Supremo sobre la materia. Doctrina que aparece bien resumida en la sentencia del Tribunal Supremo de 8 de febrero de 2018 (Grupo Inditex), dictada post Barbulescu II, donde se concluye que la prohibición expresa del uso personal de los dispositivos digitales basta para eliminar la expectativa de intimidad, si bien es preciso que la empresa respete el principio de proporcionalidad a la hora de ejercitar la vigilancia de las comunicaciones; respeto que, a juicio del Alto Tribunal, se dio en el caso enjuiciado por cuanto que i) la empresa tenía fundadas sospechas previas de un incumplimiento grave por parte del trabajador sujeto a control, ii) el empleador no examinó el contenido de los correos electrónicos de forma indiscriminada sino de manera selectiva, empleando palabras clave para la búsqueda de información relevante para la investigación, y iii) se accedió al servidor de la empresa, en la que se encuentran alojados los correos remitidos y enviados desde las cuentas corporativas de todos y cada uno de los empleados/as, sin que se accediera a ningún aparato o dispositivo particular del trabajador.

\section{Uso de dispositivos de videovigilancia y de grabación de sonidos en el ámbito laboral}

En segundo lugar, la nueva ley orgánica regula en su artículo 89 el "derecho a la intimidad frente al uso de dispositivos de videovigilancia y de grabación de sonidos en el lugar de trabajo", habiendo optado el legislador por establecer un régimen jurídico específico y diferenciado al tratamiento por el empleador de datos obtenidos a través de sistemas de cámaras o videocámaras en el lugar de trabajo.

Así, el artículo 22 de la ley regula el tratamiento de imágenes a través de sistemas de cámaras o videocámaras con la finalidad de preservar la seguridad de las personas, bienes e instalaciones, en tanto que el citado artículo 89 regula la videovigilancia con fines de control empresarial del cumplimiento por parte de los trabajadores/as y empleados/as públicos de sus obligaciones laborales.

En ambos supuestos, las personas físicas o jurídicas que traten imágenes obtenidas a través de cámaras o videocámaras deberán informar previamente sobre la colocación de las mismas, sin embargo, mientras que en el primer escenario -seguridad de las personas, bienes e instalaciones- el deber de información se entenderá cumplido mediante la colocación de un dispositivo informativo en lugar suficientemente visible (pegatina o cartel), en el segundo escenario -control del cumplimiento de las obligaciones laborales- el deber de información presenta un alcance más amplio, exigiéndose que los empleadores informen con carácter previo, y de forma expresa, clara y concisa, a los trabajadores/as o a los empleados/as públicos, y en su caso, a sus representantes, acerca de esta medida. Aunque la ley no exige que el empleador deba 
informar expresamente sobre la finalidad y el alcance concreto de la instalación, parece lógico pensar que se trata de uno de los contenidos esenciales que integran el deber de información empresarial, sin que la ley aclare, por otra parte, cuáles serían los efectos de un eventual incumplimiento del deber empresarial de información.

La relativa claridad de las reglas que acaban de indicarse queda completamente empañada en el momento en que la ley prevé como salvedad a lo expuesto el supuesto de que "se haya captado la comisión flagrante de un acto ilícito por los trabajadores o los empleados públicos". En tales casos, se entenderá cumplido el deber de informar por parte del empleador cuando existiese al menos el dispositivo al que se refiere el artículo 22.4 de la ley orgánica (pegatina o cartel).

Se trata de una excepción expresada en términos poco claros. En efecto, se genera la duda de si el legislador se refiere a cualquier acto ilícito -ilícito laboral- o solamente a actos que pudieran reputarse como delictivos. Aunque una lectura en clave tuitiva de la ley nos conduciría a interpretar restrictivamente la expresión "actos ilícitos", reservándola a los ilícitos de tipo penal, es lo cierto que tanto una interpretación literal como histórica de la ley, nos aboca a la interpretación contraria. Al respecto es preciso señalar que el primer texto del proyecto de ley presentado por el Gobierno al Congreso se refería expresamente a la "comisión flagrante de un acto delictivo", de suerte que la nueva expresión empleada por la ley obedece claramente a la voluntad de extender la excepción prevista a cualquier supuesto de comisión flagrante de un incumplimiento laboral.

De este modo, la excepción de que se trata ampararía tanto el uso para fines disciplinarios de imágenes obtenidas a través de sistemas de cámaras o videocámaras instalados con fines (exclusivos) de seguridad (personas, bienes o instalaciones), como la instalación temporal de cámaras con fines de control laboral cuando existieran fundadas sospechas previas de incumplimientos laborales. En ambos casos, el deber de información previa se entenderá cumplido con la mera colocación del dispositivo informativo (pegatina o cartel), con tal que la grabación evidencie la comisión flagrante de un incumplimiento laboral.

Interpretada en estos términos, la nueva regulación vendría a rectificar la doctrina del Tribunal Constitucional en el asunto Universidad de Sevilla (sentencia 29/2013, de 11 de febrero) y a otorgar carta de naturaleza, en cambio, a la doctrina del mismo Tribunal Constitucional en el caso Bershka (sentencia 39/2016, de 3 de marzo), aunque con un importante matiz: en adelante, con arreglo al nuevo marco legal, no parece posible la instalación de cámaras secretas, aunque existan fundadas sospechas de incumplimientos 
graves por parte de los trabajadores/as ${ }^{1}$. Ciertamente, en el asunto Bershka, el Tribunal Constitucional llega a sostener que el incumplimiento del deber de información previa no determina automáticamente la vulneración del derecho de protección de datos de carácter personal, sino que es preciso valorar las circunstancias concurrentes aplicando el principio de proporcionalidad. Aunque en el caso concreto el Tribunal Constitucional no llega a aplicar tal argumentación, en la medida en que considera debidamente cumplido el deber de información previa con la mera colocación del distintivo informativo (pegatina o cartel), es lo cierto que la afirmación del Tribunal parecía dejar abierta la puerta a la instalación de cámaras ocultas en determinados supuestos.

En todo caso, hasta qué punto esta nueva regulación supone o no una convalidación de la doctrina Bershka es una cuestión que no nos atrevemos a aventurar. Los tribunales dirán.

A todo lo dicho deben añadirse algunas consideraciones adicionales.

Por un lado, la nueva regulación, en aplicación de la doctrina constitucional en desarrollo del derecho a la intimidad, expresamente excluye la posibilidad de instalar sistemas de grabación de sonidos o de videovigilancia en lugares destinados al descanso o esparcimiento de los trabajadores/as o los empleados/as públicos, tales como vestuarios, aseos, comedores y análogos.

Por otro lado, la utilización de sistemas similares para la grabación de sonidos en el lugar de trabajo se admitirá únicamente cuando resulten relevantes los riesgos para la seguridad de las instalaciones, bienes y personas derivados de la actividad que se desarrolle en el centro de trabajo y siempre respetando el principio de proporcionalidad, el de intervención mínima y las garantías previstas para los supuestos de videovigilancia.

\footnotetext{
${ }^{1}$ La instalación de cámaras secretas en el ámbito laboral no constituye una cuestión definitivamente resuelta por la doctrina del Tribunal Europeo de Derechos Humanos. En su última sentencia sobre el particular (caso López Ribalda, sentencia de 9 de enero de 2018), el Tribunal europeo niega la posibilidad de colocar cámaras secretas, incluso cuando existan fundadas sospechas previas de incumplimientos laborales por parte de los trabajadores/as. Sin embargo, las particularidades del caso determinan que no pueda zanjarse definitivamente la cuestión, por cuanto que se trató de un control con una duración prolongada en el tiempo, sin límite temporal y durante toda la jornada laboral, y no se basó en una sospecha concreta sobre trabajadores/as concretos, sino que derivó de una sospecha general respecto de toda la plantilla que trabajaba en la zona de cajas. Este asunto ha sido elevado a la Gran Sala del Tribunal Europeo de Derechos Humanos, que dictará la sentencia definitiva. Habrá que esperar, por tanto, a este nuevo pronunciamiento judicial a fin de determinar con mayor precisión el alcance del poder de videovigilancia empresarial.
} 
Interesa poner de relieve en este punto el distinto y más restrictivo régimen jurídico aplicable a los sistemas de grabación de sonidos en el lugar de trabajo, previéndose expresamente el respeto al principio de proporcionalidad y de intervención mínima. Dicha regulación parece hacerse eco de la doctrina Casino de La Toja del Tribunal Constitucional (sentencia 98/2000, de 10 de abril).

Con todo, como se avanzó, la falta de mención expresa del principio de proporcionalidad como límite a la grabación de imágenes por parte del empleador no puede resultar óbice para seguir aplicándolo a la hora de valorar la constitucionalidad del ejercicio por parte del empresario de sus facultades de control.

Finalmente, y a diferencia de los datos obtenidos al amparo de lo dispuesto en el artículo 22 de la ley, no se prevé un plazo máximo para la supresión de las imágenes desde su captación, a salvo los sonidos conservados por los sistemas de grabación, a los que sí aplica el régimen de supresión previsto en el apartado tercero del citado artículo 22.

\section{Uso de sistemas de geolocalización en el ámbito laboral}

La nueva Ley Orgánica 3/2018, en su artículo 90, regula la utilización de sistemas de geolocalización con fines de control en el ámbito laboral, estableciendo la obligación del empleador de informar de forma expresa, clara e inequívoca a los trabajadores/as o a los empleados/as públicos, y, en su caso, a sus representantes, acerca de la existencia y características de estos sistemas, así como acerca del posible ejercicio de los derechos de acceso, rectificación, limitación del tratamiento y supresión.

Nuevamente se echa de menos la referencia expresa a la finalidad y alcance de la instalación de tales dispositivos en cuanto contenido mínimo del deber/derecho de información, a pesar de que parece lógico considerar que tales informaciones se derivan de la exigencia legal relativa a que el empleador debe informar "de forma expresa, clara e inequívoca (...) acerca de la existencia y características de estos sistemas". También se echa en falta la referencia expresa al principio de proporcionalidad como límite a la facultad empresarial de control.

Llama la atención, por otra parte, que la ley emplee adverbios distintos cuando perfila el deber de información empresarial en el caso de la videovigilancia y en el supuesto de la geolocalización. Así, en el primer caso, la ley obliga al empleador a informar a sus trabajadores/as "de forma expresa, clara y concisa", en tanto que, en el supuesto de geolocalización, la norma se refiere a que la empresa debe informar de "forma expresa, clara e inequívoca". Resulta dudoso determinar si el empleo de expresiones distintas en 
uno u otro caso obedece a la voluntad legislativa de reforzar el deber de información respecto a la geolocalización, o bien se debe a una deficiente técnica legislativa. En ambos escenarios, el resultado resulta igualmente criticable, sin que existan argumentos jurídicos de peso para defender una mayor protección en los supuestos de geolocalización.

La nueva regulación se sitúa en la línea de la doctrina judicial mayoritaria, aunque es oportuno reconocer que a nivel judicial se ha precisado aún más el alcance de la facultad de control empresarial mediante sistemas de geolocalización, exigiéndose que el control se limite al horario laboral de los empleados/as.

\section{Derecho a la desconexión digital en el ámbito laboral}

Sin duda, la novedad más destacable de la Ley en materia laboral, al menos la más mediática, es la consagración del derecho a la desconexión digital como un nuevo derecho digital de contenido laboral en el artículo 88.

Para empezar, es preciso matizar que, más que ante un nuevo derecho, nos situamos ante una expresión concreta de los derechos a la intimidad y a la integridad física y psíquica en el trabajo (en su dimensión de seguridad y salud en el trabajo). Con ello quiere decirse que, en verdad, la desconexión digital es la consecuencia necesaria del debido respeto a los citados derechos fundamentales. Esta perspectiva no debe perderse de vista y resultará especialmente relevante cuando la concreción de las modalidades de ejercicio de este derecho se desarrolle mediante negociación colectiva o, con mayor motivo, de forma unilateral por parte del empresario.

Sin embargo, no ha sido ésta la perspectiva acogida por el legislador, en la medida en que el derecho a la desconexión digital no merece la consideración de derecho fundamental, devaluándose su protección jurídica al considerarse como un derecho de configuración estrictamente legal (disposición final primera).

En todo caso, la expresa regulación legal de la desconexión digital como derecho y límite a las facultades directivas de la empresa merece una favorable acogida.

En concreto, la Ley Orgánica 3/2018 establece que los trabajadores/as y los empleados/as públicos tendrán derecho a la desconexión digital a fin de garantizar, fuera del tiempo de trabajo legal o convencionalmente establecido, el respeto de su tiempo de descanso, permisos y vacaciones, así como de su intimidad personal y familiar, debiéndose preservar dicho derecho, en particular, en los supuestos de 
realización total o parcial del trabajo a distancia, así como en el domicilio del empleado vinculado al uso con fines laborales de herramientas tecnológicas (teletrabajo).

Si la expresión o configuración del derecho no plantea dudas, no sucede lo mismo cuando se trata de regular las modalidades de ejercicio del derecho. En este punto nos topamos con una notable falta de claridad e, incluso, de incoherencia regulatoria.

El apartado segundo del artículo 88 empieza señalando que "las modalidades de ejercicio de este derecho atenderán a la naturaleza y objeto de la relación laboral, potenciarán el derecho a la conciliación de la actividad laboral y la vida personal y familiar y se sujetarán a lo establecido en la negociación colectiva o, en su defecto, a lo acordado entre la empresa y los representantes de los trabajadores". Hasta aquí, la regulación legal no genera dudas: las modalidades de ejercicio del derecho deberán atender a la regulación fijada por convenio colectivo o acuerdo de empresa.

El debate interpretativo se suscita en el apartado tercero del citado precepto legal, habida cuenta que se indica que "el empleador, previa audiencia de los representantes de los trabajadores, elaborará una política interna dirigida a trabajadores, incluidos los que ocupen puestos directivos, en la que definirán las modalidades de ejercicio del derecho a la desconexión y las acciones de formación y de sensibilización del personal sobre un uso razonable de las herramientas tecnológicas que evite el riesgo de fatiga informática".

Esta previsión difícilmente encaja con lo expresado en el anterior apartado segundo, donde se señala como instrumento regulatorio a la negociación colectiva (convenio colectivo o, en su defecto, acuerdo de empresa). Es preciso poner de relieve que la referencia a la negociación colectiva, en tanto que entraña el acuerdo entre los antagonistas sociales, se contrapone a la facultad unilateral de la empresa de elaborar una política interna sobre el derecho a la desconexión digital, máxime cuando en este último escenario solo se exige la previa audiencia de los representantes de los trabajadores, y no así un deber de consulta o negociación con la representación del personal.

La falta de coherencia entre ambos apartados se hubiera podido resolver fácilmente y de forma satisfactoria si, como sucede en el ordenamiento jurídico francés, el legislador español hubiera reformado el artículo 85 del Estatuto de los Trabajadores a fin de introducir la obligación de negociar las modalidades de ejercicio del derecho a la desconexión. De este modo, sólo en caso de fracaso de las negociaciones - presididas por el deber de negociar de buena fe-, el empresario podría elaborar de forma unilateral 
una política interna sobre el derecho a la desconexión digital. Aplicaríamos aquí la misma lógica que preside la elaboración de planes de igualdad en las empresas.

La normativa española contempla, en cambio, una regulación descafeinada del derecho a la desconexión desde la perspectiva de la defensa colectiva de los intereses de los trabajadores/as, en la medida en que no se impone un deber de negociar sobre dicho derecho digital. Así pues, el convenio colectivo o el acuerdo de empresa podrá o no regular la materia -sin que haya obligación alguna de negociarla-, recayendo en el empresario la obligación de elaborar una política interna, que podrá tener carácter unilateral desde el principio, en la medida en que la ley solamente exige la previa audiencia de la representación del personal. Eso sí, si existe convenio o acuerdo de empresa que regule las modalidades de ejercicio del derecho, la política interna empresarial deberá respetar sus directrices.

Por lo demás, es preciso reconocer que el ejercicio del derecho a la desconexión presenta perfiles difusos desde el momento en que la propia ley establece que las modalidades de ejercicio de este derecho atenderán "a la naturaleza y objeto de la relación laboral". Previsión que parece abrir la puerta a posibles restricciones del derecho cuando las funciones del trabajador/a y/o su posición jerárquica en la empresa puedan justificar una mayor laxitud horaria.

\section{Derechos digitales en la negociación colectiva}

La regulación de los derechos digitales en el ámbito laboral se cierra con la expresa habilitación a la negociación colectiva para que establezca garantías adicionales de los derechos y libertades relacionados con el tratamiento de los datos personales de los trabajadores y la salvaguarda de derechos digitales en el ámbito laboral (artículo 91).

\section{Tratamiento de datos personales en el marco de procesos de modificación estructural de sociedades o transmisión de negocio o rama de actividad empresarial}

Por último, conviene destacar que el artículo 21 de la Ley Orgánica 3/2018 establece la presunción iuris tantum de licitud de los tratamientos de datos, incluida su comunicación con carácter previo (cesión de datos), que pudieran derivarse del desarrollo de las referidas operaciones mercantiles, siempre que los tratamientos fueran necesarios para el buen fin de la operación y garanticen, cuando proceda, la continuidad en la prestación de los servicios. En el caso de que la operación no llegara a concluirse, la normativa prevé la obligación de la entidad cesionaria de proceder con carácter inmediato a la supresión de los datos. 
Fecha recepción: 21.12.2018 Fecha aceptación: 27.12.2018 